\title{
IMPACT OF ETHICAL LEADERSHIP ON FOLLOWERS' ORGANIZATIONAL DEVIANCE, MEDIATING ROLE OF PSYCHOSOCIAL SAFETY CLIMATE, MODERATING ROLE OF UNION COMMITMENT A STUDY IN THE CONTEXT OF PAKISTAN
}

\author{
RUMESA PERVEZ KHAN \\ Capital University of Science and Technology, Islamabad, Pakistan
}

\begin{abstract}
The purpose of the study was to investigate the relationship between Ethical Leadership and followers' Organizational Deviance, followed by the mediating role of Psychosocial Safety climate and moderating role of Union Commitment among the young doctors in Pakistan. Data were collected from young/junior doctors (practitioners) working in public/ private hospitals in Islamabad, Rawalpindi, and Bahawalpur. Hierarchical Regression tests were run and the results indicated that Ethical Leadership has a significant and negative relationship with Organizational Deviance. Further, the results indicated that Union Commitment moderates the relationship between Ethical Leadership and Organizational Deviance, such that greater the commitment of the members with the union would result in weakening the relationship between ethical leadership and organizational deviance. The findings also suggest that psychosocial safety climate does not mediate between ethical leadership and organizational deviance.
\end{abstract}

\section{INTRODUCTION}

According to Deal and Peterson (1999), the role of leadership is to create, encourage and refine symbols and activities that are meaningful for the organization. There are various leadership styles, like transactional, transformational, autocratic, democratic, laissez-faire, bureaucratic, despotic, servant, authentic, spiritual and ethical leadership.

For this study, the ethical dimension of leadership is being focused because of the outcomes it is said to influence (Brown \&Treviño, 2006). Workplace deviance is traditionally identified in the literature as one of the possible reactions of followers to low ethical leadership (Brown \& Treviño, 2006; Mayer et al., 2009). Thus far, researchers have assumed that ethical leadership would translate into less deviance, and that low ethical leadership would evoke more deviance for all followers alike (Mayer et al., 2009; De Hoogh and Den Hartog, 2008). Although previous findings are promising, yet an ambiguity remains as, in a study by Detert et al. (2007), the researchers could not find a significant relationship between ethical leadership and counterproductive/deviant workplace behavior. For future investigations, the researchers suggested that studies involving organizational contexts should also consider the nature or type of work and type of employees to analyze whether it affects the type of leader's influence on them; also, the outcome variables should also be taken into consideration to analyze whether it, or together with type of work and employees, impact the managerial influence on employees. Therefore, in this study, Pakistani context is taken into account, i.e., effects of ethical leadership on deviant behavior among "doctors" in Pakistan, as evident by a series of protests organized by Young Doctors Association, would be examined, which has never been investigated in this context before. These doctors in Pakistan are constantly showing resistance through their deviant behavior to protest against the perceived injustice practiced in the overall medical structure. Latest protest was observed in Islamabad on 8th September, 2015, where doctors and paramedical staff raised their voice against freezing of Health Risk Allowance. Pertaining to the current scenario, it is important to investigate what type of leader would negatively affect the deviant behavior of doctors, an ethical dilemma impacting the integrity of the profession on the whole.

Because leaders represent their organizations; therefore, when followers perceive their leaders as unethical, they retaliate against the organizations as it 
becomes a logical target for them (Bennett \& Robinson, 2000; Tepper et al., 2009; Warren, 2003). Therefore, the focus in this research is organization-directed deviance.

Leaders and followers together make up the work environment. The quality of the leadership and its followers' exchange relationship impact the quality of the work atmosphere or climate leading to favorable or unfavorable outcomes. In recent years, psychosocial safety climate, a type of organizational climate, has gained immense importance due to the high quality output it influences in organizations by their employees. According to Kidwell and Valentine (2009), if employees perceive their organizational climate as supportive, both socially and emotionally, then employees are more likely to reduce their level of deviant behaviors because of the positive attitude they will develop towards the organization. Such a type of organizational climate is known as Psychosocial Safety Climate as defined by Dollard (2007) as "policies, practices, and procedures for the protection of worker psychological health and safety". Psychological health and safety relates to psychological well-being, away from psychological risk and harm.

There are many studies which have linked psychosocial safety climate with ethical leadership and individual stressors like fatigue (e.g. Garrick, Mak , Cathcart, Winwood, Bakker \& Lushington, 2014) and interpersonal deviances like workplace bullying and harassment (e.g. Law, Dollard, Tuckey, \& Dormann, 2011). Law et al., (2011) found that Psychosocial Safety Climate was inversely related with workplace bullying and harassment, leading to reduction in psychological health issues. However, we have not been able to find many research works which have explored the relationship between PSC and Organizational Deviance; thus, we can say that the relationship between PSC and Workplace Deviance has been partially explored. In addition, there are not many studies which have investigated the intermediary role of PSC between variables. Thus, this study can contribute towards fulfilling this gap, to some extent, in the literature. Linking ethical leadership with PSC as its antecedent and reduced organizational deviance as its outcome gives it an intermediary role in this study.

As explained earlier, the relationship between ethical leadership and organizational deviance has not been found certain in a few studies; to increase the understanding of this relationship, it may be further explored by taking into consideration some prospective moderating variables (Avey, Palanski, \& Walumwa, 2010). An important topic for investigation involves the possible impact of union commitment on the negative relationship between ethical leadership and organizational deviance. As said previously, more ethical the leaders are, less deviance would be observed in the employees of that organization, but considering the present circumstances for doctors in Pakistan, where cooperative conditions between Young Doctors Association and the Government seems to be negligible, it is important to investigate whether union commitment would diminish that impact of ethical leadership on organizational deviance, i.e., employees will still show deviant behavior even though their leaders exhibit and promote ethical behaviors in the organization.

By and large the objective of this study is to develop an integrated model and test it to analyze the relationship between ethical leadership, organizational deviance, psycho-social safety climate, and union commitment. In addition, the moderating role of commitment with the union will also be studied. The graphical representation of the proposed relationship between independent, mediating, moderating and dependent variables is illustrated in the research model section of this paper. This paper ends with discussion and recommendations for future research.

\section{LITERATURE REVIEW}

\section{Ethical leadership}

Researchers had long observed that integrity/honesty, a personal/spiritual trait, would be significantly linked with followers' perceptions of leadership effectiveness, and empirical studies have validated this relationship (e.g., Reave, 2005). Other examples include the work of Den Hartog et al. (1999) and Posner and Schmidt (1992) who found that perception of a leader's integrity, truthfulness, and trustworthiness has a significant impact on its effectiveness. Similarly, cognitive trust, developed by being fair, professional and reliable (McAllister, 1995) has also been linked with leadership effectiveness (Dirks \&Ferrin, 2002). Based upon these work, Trevino et al. $(2000,2003)$ conducted an exploratory research specifically designed to answer the question and better understanding of "what the term ethical leadership means to proximate observers of executives"? For this purpose they conducted structured interviews in different industries and collected the response from twenty senior executives and twenty ethics/compliance officers. The respondents were asked to bring in mind the image of the ethical leader with whom they were familiar, and answer questions related to their leader's characteristics, motives and behaviors. The interviews revealed that a number of personal traits were associated with ethical leadership, like they were thought to be honest, altruist, fair, dependable, trustworthy, decision makers based on principles, and who care about the people and the 
society as a whole. They exhibit ethical behavior in their personal as well as professional settings. The researchers regarded these characteristics as the moral aspect of ethical leadership, and thus labelled a dimension of ethical leadership as moral manager, which represents a leader's proactive efforts to enhance the ethical behavior of the followers.

Summing up, Brown et al. (2005) defined ethical leadership as "the demonstration of normatively appropriate conduct through personal actions and interpersonal relationships, and the promotion of such conduct to followers through two-way communication, reinforcement, and decision-making". Thus, we can say that ethical leaders contour and discipline the ethical behavior of their employees, ultimately resulting in a number of positive outcomes such as followers' citizenship behavior at the organization (e.g., Kacmar, Bachrach, Harris, \& Zivnuska, 2011; Neubert, Carlson, Kacmar, Roberts, \& Chonko, 2009; Mayer et al., 2009), proactive behavior such as voice behavior (Kalshoven, Den Hartog, \& De Hoogh, 2012; Walumbwa \& Schaubroeck, 2009), consequently helping the organization's ethical climate (Mayer, Kuenzi, \& Greenbaum, 2010; Schaubroeck et al., 2012; Schminke, Ambrose, \& Neubaum, 2005), and followers' performances (e.g., Piccolo, Greenbaum, Den Hartog, \& Folger, 2010).

Ethical leadership can be distinguished from other follower-focused leadership styles that consist of both moral and amoral aspects, such as transformational leadership (Bass \& Avolio, 1994; Bass, 1990; Burns, 1978; Van Knippenberg \& Sitkin, 2013) or servant leadership (Liden, Wayne, Zhao, \& Henderson, 2008).The central aspect for this distinction is that ethical leadership is driven by moral motives that are independent of the mental frame of the perceiver. The idea that ethical leadership is based on the leader's moral motivation is supported by research, showing that ethical leaders possess moral personality traits such as a moral identity (Mayer et al., 2012) and a high social responsibility (De Hoogh \& Den Hartog, 2008). Moreover, Eisenbeiss (2012) has linked ethical leadership with four essential normative reference points, where the first one is known as humane orientation, which involves treating others with respect and dignity. The second is known as justice orientation, which involves making fair and principled based decisions. Third is known as responsibility and sustainability orientation, which involves a leader's concern in their long-term views for the welfare of the people and the society as a whole. And fourth is known as moderation orientation, which refers to abstinence and humility of the ethical leader. Together, these orientations represent universally shared moral norms underlying ethical leadership.

\section{Ethical leadership and Organizational Deviance}

Ethical leaders are the type of leader who can influence their employees/followers in different ways. They are responsible for observing and implementing the ethical standards in their organization. For establishing such standards, they become role models for the ethical behavior, or they assure that ethical codes are being followed through reinforcement (Mayer et al., 2012; Brown et al., 2005; Weaver, Trevino, \& Agle, 2005; Trevino, Hartman, \& Brown, 2000; Walumbwa et al., 2011). Depending on the quality of leader-follower relationship, the ethical behavior of the leaders is reciprocated accordingly (Brown \&Treviño, 2006; Walumbwa et al., 2011). Ethical leaders also increase follower organizational identification (Van Knippenberg, Van Knippenberg, De Cremer, \& Hogg, 2004); an element which enhances a follower's motivation to achieve collective goals or exhibit such a behavior that it benefits the organization (Walumbwa et al., 2011). Altogether, high ethical leadership seems to motivate followers to reciprocate with moral behavior, yet low ethical leadership motivates followers to display negative behavior (Kacmar et al., 2011; Weaver et al., 2005) either through modelling, breaches in the exchange relationship, or reduced identification.

In literature, this display of negative behaviors have been labelled with different names, e.g., some researchers call it as an antisocial organizational behavior, while others call it as workplace deviance, organizational misbehavior, dishonesty, employee withdrawal, counterproductive behavior or dysfunctional behavior, to name a few (Everton et al., 2007).Robinson and Bennett (1995) conceptualized workplace deviance based on Kaplan's (1975) view on particular norms of the organization. Robinson and Bennett (1995) defined workplace deviance as any intentional behavior that goes against the norms of the organization, posing threat to the well-being of the organization and the members of it. Thus, workplace deviance is not defined in terms of a standard of moral behaviors as shaped by policies, procedures and rules, rather it is the deviation from such standards that when an individual is considered to be in the loop of displaying deviant workplace behaviors. In addition, this framework also stresses that to be considered deviant, the behavior should be of such a nature that it poses threat or harm to the well-being of the organization or its members; thus, social blunders, or poor manners can be excluded from this framework. Being confronted with low ethical leadership is likely to be a frustrating experience for some followers, and can be vented out in several ways (Gils, Quaquebeke, 
Knippenberg, Dijkec \& Cremer, 2014). Followers could react to the person displaying the unethical behavior directly. However, reactions of the followers to their leader's unethical behavior can be a restricted one due to less authority and power followers have as compared to their leaders. Therefore, deviant behavior is often directed at the organization, in the form of falsifying receipts or putting lower effort into the job, or at the organization's members, in the form of interpersonal aggression toward others in the organization (Bennett\& Robinson, 2000; Robinson \& Bennett, 1995). Indirectly retaliating toward the organization through deviant behavior often seems a safer choice (Mayer et al., 2009; Detert, Treviño, Burris, \& Andiappan, 2007).

Thus far, researchers have assumed that ethical leadership, where followers are treated with equality and respect, would translate into less organizational deviance and vice- versa.

Hence the following hypothesis

Hypothesis 1. Ethical leadership has a negative relationship with Organizational Deviance

\section{Mediating role of Psychosocial Safety Climate}

\section{Ethical leadership and Psychosocial Safety Climate}

Psychosocial safety climate (PSC) is defined as "shared perceptions of organizational policies, practices and procedures for the protection of worker psychological health and safety, that stem largely from management practices" (Law, Dollard, Tuckey \& Dormann, 2011). According to Dollard (2011), the concept of work stress, organizational climate, and psychosocial risk together made up the concept known as psychosocial safety climate. It is a specific dimension of organizational climate which relates to an employee's freedom from psychological risk and harm at its workplace (Dollard \& Bakker, 2010). Thus, it reflects the concern that management should have to safeguard psychological health of the workers, rather than giving priority to production demands which may pose a threat to psychological well-being of the employees at some point in time (Dollard \& Bakker, 2010). According to James et al. (2008),PSCmeasure stems mostly from the idea that people credit meaning to their work conditions, which includes their salary, administrative frameworks, co-worker treatment, and an environment of justice. As being what is indicated, routes in which PSC can get to be unmistakable to people include correspondence frameworks at all levels of the organization (e.g., for reporting poor mental well-being at work) and effectively including all layers of the association in work stress aversion (Dollard \& Bakker, 2010).
PSC relates to a work environment for employees' psychological health and safety, and includes four interconnected, yet very significant principles (Dollard, 2011; Hall et al., 2010). The first principle relates to the ability of senior management commitment and support for stress aversion. The second principle relates to the importance that management gives to psychological health and safety, as opposed to productivity demands. The third principle involves upward and downward communication to aware every employee regarding the importance of psychological health and safety. The fourth principle relates to the extent to which managers as well as employees are involved and contribute towards psychological health and safety (Dollard, 2011; Hall et al., 2010). Employees' perception of these principles, at a departmental level or an organizational level, is aggregated to quantify PSC.

According to Edmondson (1999), psychological well-being alludes to shared convictions among work unit individuals that it is alright for them to participate in interpersonal risk taking. As indicated by Edmondson, psychological security goes past seeing and encountering greater levels of interpersonal trust; it additionally portrays a work atmosphere based on mutual respect/regard, one in which individuals are open to communicating their disparities. Leaders are crucial for uprooting the hurdles that frequently debilitate followers from communicating their worries, concerns, and different thoughts. In climates high in psychological safety, leaders, additionally, effectively convey the significance of such a safety behavior, and assure that it won't have negative consequences for the individual or the work unit. In this regard, ethical leadership may be especially vital, but then this capacity is overlooked in the writing. According to Brwon et al. (2005), ethical leaders with higher moral standards value fair and honest associations with their adherents/followers. They behave according to their fundamental beliefs and values, as opposed to feeling pressurized and reacting to external demands. At the point when leaders associate with followers with openness and honesty, mutual respect and interpersonal trust is advanced between both the leaders and the followers; and not just between them, but among the followers as well.

Therefore, when followers believe that their leaders have adequate ability, generosity, and integrity, which are key establishments of a worker's trust on its leader (Mayer, Davis, \& Schoorman, 1995), they will be more agreeable about taking part in interpersonal risk taking on the grounds that they perceive their leaders would not unjustifiably rebuff them when risk taking would lead to an unfavorable result (Dasborough \& Ashkanasy, 2002; Weierter, 1997). This suggests a positive relationship between ethical leadership and followers' psychological 
safety.

Thus, we derive our hypothesis:

\section{Hypothesis 2a. Ethical leadership has a positive relationship with Psychosocial Safety Climate}

\section{Psychosocial Safety Climate and Organizational Deviance}

As the present circumstances of doctors in Pakistan, where protests are frequently observed, it is critical for organizations to better comprehend the elements that impact employees to show such deviant behavior. According to Riggle (2007), this growing interest in understanding employees and their behavior has prompted researchers to investigate employees' perceptions of organizational climate as well, as it has significant outcomes for both the members and the organization. The climate at the workplace influence workers' conduct, states of mind, motivation and capabilities, which is anticipated to impact organizational profitability eventually (Adeniji, 2011). This is to say that organizational climate is viewed as essential element in the life of organization because of its unmistakable impacts, and its relation with the administrative practices. It influences an individual's job satisfaction and commitment, leading to better performance, thus influencing the accomplishments of the association and its capacity to proceed (Al-Saudi, 2012). Researchers now understand the importance of organizational climate to impact employees' attitudes and behaviors; therefore, they are expanding their considerations in the domain of organizational behavior (Holloway, 2012).

Analysts propose that organizational climate is connected with positive behaviors like organizational citizenship behavior, and negative behaviors like dysfunctional or counterproductive or deviant behavior. (Scheuer, 2010; Farooqui, 2012; Al-Saudi, 2012; Fagbohungbe et al., 2012; Wolf et al., 2012; Bellou \& Andronikidis, 2009). As individuals have a tendency to understand and blend in with the climate of the organization, it has a critical effect on their conduct (Vardi, 2001). Consequently, if employees feel support from the organization in the form of employee oriented policies, making them feel psychologically safe, they would be more inclined towards creative and supportive behavior when confronted with troubling issues. On the other hand, if employees see their work environment as unjust, unfair and non-supportive, they would be more inclined to get upset and baffled, and would display negative conduct like deviant behaviors (Wolf et al., 2012). An empirical study illustrated that employees' perception of injustice and unfair treatment at the workplace leads to negative emotions such as resentment, anger and outrage, and thus to behavioral reactions, like organizational retaliatory behavior or deviant workplace behavior (Skarlicki \& Folger, 1997). Likewise, Cropanzano and Baron (1991) connected unfair treatment to emotions and ultimately conflict at the workplace. Cropanzano, Howes, Grandey, and Toth (1997) also related deviant/counterproductive work behaviors to elevated job tensions, fatigue and burnout. In other words, psychological heath problems which are attributed to organizational climate with low psychosocial safety, leads to deviant workplace behaviors. All the explanation above suggests a negative relationship exists between psychosocial safety climate and organizational deviance. Thus, the following hypothesis:

\section{Hypothesis 2b. Psycho-social Safety Climate has a negative relationship with Organizational Deviance.}

A key element of social exchange theory is that the quality of the exchange relationship between the two entities is the most proximal reason for their behavior. This is to say that employees choose which behavior to exhibit on the premise of the sort of connection they have with the other individual.

It is argued that ethical leadership promotes positive behavior among employees like interpersonal helping or citizenship behavior (Brown et al., 2005). When employees are dealt with reasonably by their leaders, they are prone to consider their association with their leader in terms of social exchange, instead of economic exchange. One approach to respond to such treatment is to indulge in citizenship behavior. On the other hand, employees who are treated unfairly by their leaders would reciprocate by exhibiting deviant behaviors. . In addition, it makes sense that employees high in psychological safety, because of the moral conduct of their leaders, would perceive lesser threat to their own particular welfare while communicating their ideas, worries and concerns. An empirical evidence for this relationship was given byTangirala and Ramanujam (2008), when they found out that stronger the climate of the procedural justice, lesser would be the silencing of opposing/disagreeing opinions amongnurses. Individuals treated with fairness, respect and mutual understanding perceive their climate to be high in psychosocial safety, and in turn are less likely to indulge in counterproductive deviant behavior. Hence, the explanation above about the effects of ethical leadership on psychosocial safety climate and employee organizational deviant behavior, and the linkage between psychosocial safety climate and employee organizational deviant behavior suggest the 
following hypothesis:

Hypothesis 2c. The negative relationship between ethical leadership and organizational deviance is partially mediated by employees' perceptions of psychosocial safety climate.

\section{Moderating role of Union Commitment}

In Pakistan, given the circumstances of lack of service structure, security and low pay, an informal body namely the Young Doctors' Association (YDA) stepped forward with a motive to safeguard the rights of the doctors (of the Punjab province of Pakistan), by negotiating with the government for resolution of their problems; yet, the government's failure to adequately deal with the situation has resulted in frequent protests by doctors and deviant behaviors at the workplace. The previous literature also highlights that job dissatisfaction, rather than the union's ability to promote workplace justice, is the main cause to union organizing and militant participation. (e.g. Kochan 1979; Barling et al. 1992; Kuruvilla et al.1990). Kelly (1998) attributes injustice to be the root cause of collective action, regardless that it is organized by a union or other body, or is planned or decided in the spur-of-the-moment situation. Under adversial conditions where union and organization interests are in sharp conflict, commitment to union would diminish organizational commitment's relationship with positive behavioral outcomes (Larson \& Fukami, 1984).

Union commitment is caused by both organizational and individual factors and bearing many organizational implications (Bamberger, Kluger, \& Suchard, 1999). Among them, Iverson \& Kuruvilla, (1995) observed positive and negative affectivity of employees, job related variables such as job dissatisfaction and organizational variables like leadership behavior are mainly causing union commitment. Felt grievances and dissatisfaction with management are positively associated with militant union participation of employees which is an outcome of union commitment (Parks et al., 1995). Thus, we can say that positive attitude towards the union develops because of dissatisfaction with employer organization; therefore it reasons the supporting role for militant participation of members. This is further evident in the "dual loyalty research" of the 1950s which tested the hypothesis that positive attitudes towards the union would lead to negative attitudes towards the employer (Dean, 1954 ; Kerr, 1954 ; Purcell, 1954 ; Stagner, 1954) . Militant participation is defined as any activity with respect to union individuals to withhold work movement, for example, a strike or work slowdown. A strike is a transitory stoppage of work by union representatives to express an intense grievance, and work slowdown is an intentionally planned activity to reduce productivity. Both of these forms to show resistance also lie under the typology of deviant workplace behavior. Intentional work slowdown comes under the category of Production Deviance, and aim for temporary stoppage of work can be achieved by outright protests including sabotaging equipments which comes under the category of Property Deviance. Militant participation in which the concept of organizational deviance is embedded signifies the relationship between union commitment and organizational deviance; militant participation being an eventual outcome of union commitment.

Conley's (1990) study of teacher propensity to take militant action with regard to workplace control concluded that militancy was best understood in terms of teachers' perceived integration into the school organization. Teachers who perceived little feedback, influence, and satisfaction with supervisor, along with accompanying high role conflict, were more likely to increase their commitment to the union and show support to militant participation.

Correlations have been found between militancy and both satisfaction with union leaders (Martin, 1986) and commitment, though the latter may be moderated by age (Black, 1983).

It would be misrepresenting if individuals' union commitment is consigned exclusively to a financial trade (economic exchange). Therefore, the concept of social exchange is embedded to explain the relationship between a member and the union, as, according to Sinclair and Tetrick (1995), it refers to the socioemotional support provided by the union to its members.

Referring back to the situation of young doctors in Pakistan, using the framework of Social Exchange theory we argue that if union is providing the perceived benefits to the employees such that their problems and concerns are being communicated in the form of militant participation / partial organizational deviance, protecting the rights or ensuring a just system in the workplace, then ethical leadership will not help as much to reduce organizational deviance in the workplace. In other words, union commitment will weaken the relationship between ethical leadership and organizational deviance in such a manner that higher level of union commitment will weaken this relationship.

Thus we derive the following hypothesis,
Hypothesis 3. Union commitment moderates the relationship between ethical leadership and organizational deviance, such that employees with strong union commitment would still exhibit organizational deviant behaviors even though leadership is ethical. 


\section{THEORETICAL FRAMEWORK}

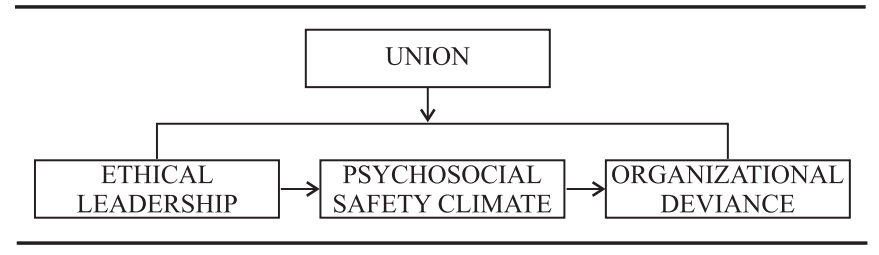

\section{RESEARCH METHODOLOGY}

\section{Sampling}

A target of 300 respondents to fill the questionnaires was set, but data could be obtained from 178 respondents. The target population of this research was young/junior doctors (practitioners) working in public and private hospitals in Islamabad, Rawalpindi, and Bahawalpur. In this study, based on limited resources, two types of nonprobability sampling techniques have been used to gather the required data from the sample. One is convenient sampling technique and second is snow ball sampling technique. The sample consisted of 178 doctors. About 67 percent males and 32 percent females filled up the questionnaire. They fell mostly in the age bracket of 36 -40 years. Almost 59 percent of the respondents were post graduates and majority of the respondents had work experience between 1 and 3 years.

\section{INSTRUMENTATION}

\section{Ethical Leadership}

Ethical leadership was measured using the ten-item ELS scale by Brown, Treviño, and Harrison (2005). The instrument exhibit high reliability and stable unidimensionality. The authors state that this short measure of Ethical Leadership can be readily utilized into survey research. Examples of the items are "My leader conducts his/her personal life in an ethical manner." And "My leader defines success not just by results but also the way that they are obtained." A five point ranging scale of strongly disagree (1) to strongly agree (5) was used.

\section{Psychosocial Safety Climate}

It is proposed that Psychosocial Safety Climate has four domains, namely, Management Commitment, Priority, Communication and Participation and Involvement (Hall, Dollard, \& Coward, 2010). After systematic testing of the scale, the researchers stated that this instrument can be used upon a multiple range of occupations. For this study, the instrument has been taken as a single construct. Examples of items include: "In practice, the prevention of stress involves all levels of the organization"; "In my organization my contributions to resolving occupational health and safety concerns regarding psychological well-being are listened to". Responses in this study were taken on a 5-point Likert scale ranging from 1 (strongly disagree) to 5 (strongly agree).

\section{Union Commitment}

Union commitment was measured using a 13 items questionnaire established by Kelloway, Catano, and Southwell (1992). These items were divided into three dimensions namely, Loyalty, Willingness to work for the Union and Responsibility to the Union. Examples of the items are: "it is every member's responsibility to see that the other member live up to the collective agreement" and "It is every member's duty to support or help another worker use the grievance procedure". The items were measured on a 5 point Likert scale ranging from 1 as Strongly Disagree to 5 as Strongly Agree.

\section{Organizational Deviance}

Organizational deviance is one of the dimensions of workplace deviance. The other dimension is interpersonal deviance. For the current study only items related to organizational deviance have been used, as in an unjust environment, employer organization becomes a logical target for retaliation by employees. A 12 items instrument to measure organizational deviance was developed by Bennett and Robinson (2000), which measures the frequency in which the respondents engage in behaviors that are harmful to the organization; hence, a 5 point Likert scale was used in which 1 represented Never and 5 represented Always. Bennet and Robinson (2000) found internal reliability of the scale to be 0.81 . Sample items from the scale include: "take property from work without permission", "intentionally work slower than one could have worked".

\section{RESULTS}

In order to find support for the direct relationships, mediation and moderation of the proposed model, correlation tests were run on SPSS. Further, Hierarchical Regression tests were run in order to either validate or reject the proposed hypothesis.

The table (1) shows mean, standard deviation, and correlation amongst the variables under study. According to the table, Ethical leadership is negatively and significantly correlated with Organizational Deviance as $r=-.188$ and $p<0.05$. Ethical Leadership is positively and significantly correlated with Psychosocial Safety Climeta as $\mathrm{r}=.178$ and $\mathrm{p}<0.05$. 
TABLE 1

Mean, Standard Deviation, Correlation

\begin{tabular}{llllllll}
\hline & Variables & Mean & S.D & $\mathbf{1}$ & $\mathbf{2}$ & $\mathbf{3}$ & $\mathbf{4}$ \\
\hline 1 & EL & 4.20 & 0.80 & 1 & & & \\
2 & PSC & 3.09 & 0.96 & $.178^{*}$ & 1 & & \\
3 & UC & 3.62 & 0.76 & $.265^{* * *}$ & $.182^{*}$ & 1 & \\
4 & OD & 2.37 & 1.19 & $-.188^{*}$ & -.064 & $.306^{* * *}$ & 1 \\
\hline
\end{tabular}

$N=178, * P<0.05, * * P<0.01, * * * P<0.001$ ( EL $=$ Ethical Leadership, PSC $=$ Psychosocial Safety Climate, UC $=$ Union Commitment, $O D=$ Organizational Deviance

TABLE 2

Hierarchical Regression Analysis for Determinants of Ethical Leadership

\begin{tabular}{lcccccc}
\hline Predictors & \multicolumn{2}{c}{ Psychosocial Safety Climate } & \multicolumn{3}{c}{ Organizational Deviance } \\
& $\boldsymbol{\beta}$ & $\mathbf{R}^{\mathbf{2}}$ & $\boldsymbol{\Delta} \mathbf{R}^{\mathbf{2}}$ & $\boldsymbol{\beta}$ & $\mathbf{R}^{\mathbf{2}}$ & $\boldsymbol{\Delta} \mathbf{R}^{\mathbf{2}}$ \\
\hline Step I: & & & & & & \\
Control Variables & & .054 & & & .293 & \\
Step II: & & & & & & \\
Ethical Leadership & $.347^{* * *}$ & .121 & $.067^{* * *}$ & $-.414^{* *}$ & & \\
Psychosocial Safety & & & & -.108 & & \\
Climate & & & & & & \\
Union Commitment & & & & $.617^{* *}$ & .411 & $.118^{* *}$ \\
\hline
\end{tabular}

$n=178$, control variables are gender, age, experience, qualification and hospital type.

$+p<.10, \quad * p<.05, * * p<.01, * * * p<.001$

Psychosocial Safety Climate is negatively but insignificantly correlated with Organizational Deviance as $r=-.064$ and $p>0.05$. Union commitment is positively and significantly correlated with Organizational Deviance as $\mathrm{r}=.306$ and $p<0.001$.

The above table (Table 2) shows hierarchical regression analysis for determinants of Ethical Leadership.

According to the table (Table 2) there is a negative and significant relationship between the independent variable, which is Ethical Leadership, and the dependent variable, which is Organizational Deviance $(\beta=-.414$, $p<0.01)$. Ethical Leadership also has a significant but positive relationship with the mediator, i.e., Psychosocial Safety Climate $(\beta=.347, \quad p<0.001)$. However, Psychosocial Safety Climate does not have a significant relationship with Organizational Deviance $(\beta=-.108$, $p>0.05)$. The moderator, Union Commitment, has a positive and significant relationship with Organizational Deviance $(\beta=.617, p<0.01)$.

According to Baron and Kenny (1986), we need to establish three conditions in order to determine whether mediation occurs or not. First, the independent variable (Ethical Leadership) should predict the dependent variable (Organizational Deviance). Second, the independent variable should predict the mediator
(Psychosocial Safety Climate). Third, the mediator should predict the dependent variable. Here, the first two conditions are being met, but our mediator, i.e. Psychosocial Safety Climate is not predicting the dependent variable, i.e. Organizational Deviance. Hence, Psychosocial Safety Climate is partially mediating the relationship between Ethical Leadership and Organizational Deviance.

Table 3 shows the regressed analysis of moderation. As $\mathrm{R}^{2}$ represents variance in the model, and $\Delta \mathrm{R}^{2}$ represents change in variance due to introduction of a new variable; therefore, increase in $\mathrm{R}^{2}$ at each stage is reflecting that the introduced variable has a significant impact.

According to the results, the moderator, i.e., Union Commitment having $\beta$ value as .135 with significance value below .01 indicates a positive and a significant impact on the relationship between Ethical Leadership and Organizational Deviance; thus saying that greater the positive impact of moderator, it will further weaken the negative relationship between independent and dependent variable. In other words, higher the union members' commitment to their union, lesser would be the impact of their Leader's Ethical behavior on Organizational Deviance. Thus, our last hypothesis gets accepted. 
TABLE 3

Results of Hierarchical Moderated Regression Analysis

\begin{tabular}{llrr}
\hline Predictors & \multicolumn{3}{c}{ Organizational Deviance } \\
& $\boldsymbol{\beta}$ & $\mathbf{R}^{2}$ & $\Delta \mathbf{R}^{2}$ \\
\hline
\end{tabular}

Moderator Analysis

Ethical Leadership

Step I:

Control Variables

Step II:

Ethical Leadership $\quad-.280 *$

Union Commitment $.597 *$ * $\quad 376 \quad .136 * *$

Step III:

Ethical Leadership x $.135^{* *} \quad .393 \quad .035^{* *}$

Union Commitment

$n=178$, control variables are gender, age, experience, qualification and hospital type.

$+p<.10, \quad * p<.05,{ }^{* *} p<.01,{ }^{* * *} p<.001$

\section{DISCUSSION AND CONCLUSION}

The results validated the hypothesis 1 . They indicated a negative and significant relationship between Ethical Leadership and Organizational Deviance. This result is in line with many previous studies. For example, Mayer, Kuenzi, Greenbaun, Bardes, and Salvador (2008) conducted their research on employees from 160 different organizations in Southeast U.S. and found out that while ethical behavior is important at all levels of the organization, yet the ethical behavior of the direct supervisor is most important in influencing more positive behavior like organizational citizenship behavior, and less deviant behavior among employees. Their hypothesized relationship was significant at $(\beta=-.44, p<.001)$. Gills, Quaquebeke, Knippenberg, Digke and Cremer (2015) conducted two studies; one consisted of a sample size of 90 employees and their supervisors of a Dutch Research panel, and the second experimental study consisted of 96 Dutch university students, and in both the studies the conclusion was the same, i.e., followers with high moral attentiveness tend to exhibit more deviant behaviors to low ethical leadership as compared to those who have low moral attentiveness.

The social exchange theory also stresses and supports the hypothesis that employees reciprocate in the same fashion (positive/negative) as treated by their supervisors. If the supervisors are ethical and promote ethical behavior, the response would also be of a positive nature, i.e., employees would exhibit positive behaviors, which means there would be less room for negative behaviors.

The result also validated our second prediction (hypothesis 2a). It indicated a positive and highly significant relationship between Ethical Leadership and Psychosocial Safety Climate. This result is in line with the previous study by Walumbwa and Schaubroeck (2009) who found out that the ethical leadership has a positive relationship with employee's constructive behavior (voice behavior)mediated by a climate of psychological safety. This implies that ethical leadership influence the feeling of confidence in employees for expressing their views about work process without fear of unpleasant consequences, reflecting their perception of psychological safety induced by their ethical leaders.

Contrary to our expectation, hypothesis $2 \mathrm{~b}$ was rejected. This means that Psychosocial Safety Climate does not reduce deviant behaviors directed towards the organization by employees. Past studies have linked psychosocial safety climate with ethical leadership and individual stressors like fatigue (e.g. Garrick, Mak, Cathcart, Winwood, Bakker, \&Lushington, 2014) and interpersonal deviances. For example, Law, Dollard, Tuckey, and Dormann (2011) found that Psychosocial Safety Climate was negatively associated with workplace bullying and harassment (interpersonal deviances) and in-turn psychological health problems. Through this study, we wanted to explore the relationship between Psychosocial Safety Climate and other dimension of Workplace Deviance, i.e., Organizational Deviance. One possible explanation for the hypothesis rejection is injustice and unemployment situation in Pakistan. Here, the law and order system remains beleaguered by continuous inequity, unfairness, operational inefficiencies, exploitation by power and money, lack of resources, and corruption by the higher authorities in almost every industry, as a result of which a great mistrust prevails in the hearts of common Pakistani citizens. This mistrust in the institutions and its employers is one of the biggest hurdles in developing Pakistan as a civic society. We see unrest among people in Pakistan every day. Some are agitated, frustrated and some resist by showing deviant workplace behaviors like work slowdown and protest. This kind of unrest is observed among doctors community in Pakistan repeatedly. Injustice is said to be the root cause of collective action (Kelly, 1998). In a study by Ahmed, Kiyani, and Hashmi (2013), injustice was found to be a significant predictor of workplace deviance among nurses and doctors in Pakistan. The doctors were found to be more deviant than the nurses because of the higher expectations in terms of salary, compensation and benefits. Beside injustice, there is also a problem of lack of job opportunities in Pakistan; therefore, employees stick to their jobs even after great discontent. Due to these two very important factors, psychological safety is no longer very important for employees in Pakistan as compared to the employees in the Western world. People in the west do not have to worry about inequality, promotions, job 
insecurity or unemployment issues, which is the reason why psychosocial safety climate is vital for them. On the other hand, there are adverse factors that need to be addressed first in Pakistan for the impact of Psychosocial Safety Climate to reduce Organizational Deviance to take effect.

Since the relationship between Psychosocial Safety Climate and Organizational Deviance could not be established, we could not run the mediation steps, as according to Baron and Kenny (1986), we need to first confirm three conditions; first, the independent variable (Ethical Leadership) should predict the dependent variable (Organizational Deviance); second the independent variable should predict the mediator(Psychosocial Safety Climate); and third, the mediator should predict the dependant variable. The first two conditions were met, but out mediator, i.e., Psychosocial Safety Climate was not predicting the dependent variable, i.e., Organizational Deviance. Hence, Psychosocial Safety Climate is partially mediating the relationship between Ethical Leadership and Organizational Deviance.

The result of our study validated our last hypothesis (3); there is a significant impact of Union Commitment on the relationship between Ethical leadership and Organizational Deviance, such that increase in union commitment would weaken the negative relationship between ethical leadership and organizational deviance. Thus saying that increase in union commitment would limit the impact of ethical leadership, which otherwise plays an important role in minimizing the deviant behavior directed towards the organization by its employees. A possible explanation of such a result can be attributed to Social Exchange theory. Individuals reciprocate to behaviors with more perceived benefits. If employees perceive that their leaders are legitimate role models who exhibit and provide rationale for the benefits of exhibiting normatively appropriate behavior, employees would, inturn, reciprocate that behavior in the form of helping or citizenship behavior. They would feel indebted to fair, honest and caring behavior of their ethical leaders that, if not reciprocated with more citizenship behavior, the least likely would be that they would exhibit negative behavior at workplace like organizational deviance. However, when organization and individual's interest are in sharp conflict, then employees feel the need to become the member of the union because of the greater perceived benefits provided by the union. The conflict usually arises when employees feel perceived inequity and injustice, and when unions provide them with the support to voice against an unjust environment (through militant participation) and greater perceived probability or restoring equity at the workplace. The members would reciprocate by increasing their commitment to the union based on greater perceived benefits as compared to perceived benefits by behaving ethically.

\section{Research Limitations and Future Research Directions}

Out of 1142 hospitals all over Pakistan, only 12 were covered in Bahawalpur, Islamabad and Rawalpindi. This is due to limitation of time, travelling resources and references. With limited references, all the doctors could not be reached. Another reason is the busy schedule of the doctors and their disinterest in research studies that even hospitals within reach were not welcoming. For this study, convenience and snow balling sampling technique has been used to collect data, thus every recipient did not have an equal probable chance of getting selected for this study. Moreover, this study covers one industry only, i.e., health care industry; therefore, we cannot assume the same results for other industries as well. Furthermore, the recommendations are chalked out according to this particular industry; it will cater to particular needs and cannot be implemented in other industries without proper research. The results have been carefully analyzed keeping the context in perspective, i.e., Pakistan. Therefore, we can expect similar results in countries with cultures similar to ours, but this cannot be assumed for studies in countries with different cultures. All this limits the generalization of our results.

Following are some suggestions for future research work:

According to Barling, Weber, and Kelloway (1996), training is an important factor in developing transformational leaders. Therefore, Brown and Trevino (2006) suggested that Organizational leadership training can be helpfulin developing moral reasoning of ethical leadership. Hence, Organizational Leadership Training can be taken as an antecedent of ethical leadership to enhance their moral reasoning and better prepare them to handle complex ethical issues, leading towards reduced workplace deviance by the employees. Moreover, a metaanalysis by Dirks and Ferrin (2002) found that trust in leadership was strongly associated with employees' job satisfaction, citizenship behaviors and performance. Therefore, Trust in leadership can be taken as a mediator between Ethical Leadership and Workplace Deviance, or ethical leadership and citizenship behavior/job satisfaction/performance of the employees.

According to Resick, Hanges, Dickson, and Mitcheluson (2006), the components of ethical leadership vary across cultures. Therefore, Brown and Trevino (2006) suggested that ethical leadership should be further explored in different cultures to have a greater understanding of this phenomenon.

The model used in this study can be amended as suggested above and used on a larger sample size in the same health care industry of Pakistan. Respondents'have 
been reluctant in recording their deviant behavior during the survey. For more accurate results, the dyadic data analysis can be done where deviant behaviors of employees should be reported by the leaders. In addition, since union commitment as a moderator has been a significant finding in this study, the same moderator should be used to study the impact of suggested relationships in higher education sector of Pakistan. In public universities, the student union influences greatly of what happens in their universities; therefore, the research study may produce interesting results and contributions to existing literature.

\section{REFERENCES}

Abbasi, I. N. (2014). Protest of doctors: a basic human right or an ethical dilemma. BMC Medical Ethics, 15(1), 1-9.

Adeniji, A. A. (2011). Organizational climate as a predictor of employee job satisfaction: evidence from covenant university. Business Intelligence Journal, 4(1), 151-166.

Ahmed, W., Kiyani, A. A., \&Hashmi, S. H. (2013).The study on organizational cynicism, organizational injustice \& breach of psychological contract as the determinants of deviant work behavior. Актуальніпроблемиекономіки, (2), 145-154.

Akinbode, G. A., \& Fagbohungbe, O. B. (2012). Leadership and Organizational Factors as Predictors of Employees Organisational Commitment in Nigeria: An Empirical Analysis. Business and Management Research, 1(2), 48-68.

Al-Saudi, M. A. (2012). The Impact of Organizational Climate upon the Innovative Behavior at Jordanian Private Universities as Perceived by Employees: A Field Study. International Business and Management, 5(2), 14-27.

Appelbaum, S.H., Iaconi, G.D. \&Matousek, A. (2007). Positive and negative deviant workplace behaviors: causes, impacts, and solutions, Corporate Governance, 7(5): 586-598.

Avey, J. B., Palanski, M. E., \&Walumbwa, F. O. (2011). When leadership goes unnoticed: The moderating role of follower self-esteem on the relationship between ethical leadership and follower behavior. Journal of Business Ethics,98(4), 573-582.

Bamberger, P. A., Kluger, A. N., \&Suchard, R. (1999). Research Notes: TheAntecedents and Consequences of Union Commitment: A Meta-Analysis. Academy of Management Journal, 42(3), 304-318.

Barkin, S. (1975).Worker militancy and its consequences, 1965-75: new directions in Western industrial relations (Vol. 30). Praeger Publishers.

Barling, J., Fullagar, C., Kelloway, E. K., \& McElvie, L. (1992). Union loyalty and strike propensity. The
Journal of Social Psychology, 132(5), 581-590.

Barling, J., Weber, T., \& Kelloway, E. K. (1996). Effects of transformational leadership training on attitudinal and financial outcomes: A field experiment. Journal of Applied Psychology, 81(6), 827-832.

Baron, R. M., \& Kenny, D. A. (1986). The moderatormediator variable distinction in social psychological research: Conceptual, strategic, and statistical considerations. Journal of Personality and Social Psychology, 51(6), 1173-1182.

Bass, B. M., \& Stogdill, R. M. (1990). Bass \& Stogdill's handbook of leadership: Theory, research, and managerial applications. Simon and Schuster. 3rd edition, p126.

Bass, B. M., \&Avolio, B. J. (1994). Transformational leadership and organizational culture. The International Journal of Public Administration, 17(3-4), 541-554.

Bellou, V., \& Andronikidis, A. I. (2009). Examining organizational climate in Greek hotels from a service quality perspective. International Journal of Contemporary Hospitality Management, 21(3), 294-307.

Bennett, R. J., \& Robinson, S. L. (2000). Development of a measure of workplace deviance. Journal of Applied Psychology, 85(3), 349.

Blackburn, R. M., \&Prandy, K. (1965). White-collar unionization: a conceptual framework. British Journal of Sociology, 111-122.

Blanchard, A. L., \&Henle, C. A. (2008).Correlates of different forms of cyberloafing: The role of norms and external locus of control. Computers in Human Behavior, 24(3), 1067-1084.

Blau, G. (1995). Influence of group lateness on individual lateness: A cross-level examination. Academy of Management Journal, 38(5), 1483-1496.

Brown, M. E., \& Treviño, L. K. (2006). Socialized charismatic leadership, values congruence, and deviance in work groups. Journal of Applied Psychology, 91(4), 954-962.

Brown, M. E., Treviño, L. K., \& Harrison, D. A. (2005). Ethical leadership: A social learning perspective for construct development and testing. Organizational Behavior and Human Decision Processes, 97(2), 117-134.

Burns, J.M. (1978). Leadership. New York: Harper \& Row.

Conley, S. (1991). Review of research on teacher participation in school decision making. Review of Research in Education, 225-266.

Cooke, W. N. (1983). Determinants of the outcomes of union certification elections. Industrial \& Labor Relations Review, 36(3), 402-414.

Cortina, L. M., Magley, V. J., Williams, J. H., \& 
Langhout, R. D. (2001). Incivility in the workplace: incidence and impact. Journal of Occupational Health Psychology, 6(1), 64-80.

Coyle, I. R., Sleeman, S. D., \& Adams, N. (1996).Safety climate. Journal of Safety Research, 26(4), 247-254.

Cropanzano, R., \& Baron, R. A. (1991). Injustice and organizational conflict: The moderating effect of power restoration. International Journal of Conflict Management, 2(1), 5-26.

Cropanzano, R., \& Mitchell, M. S. (2005). Social exchange theory: An interdisciplinary review. Journal of Management, 31(6), 874-900.

Cropanzano, R., Howes, J. C., Grandey, A. A., \&Toth, P. (1997).The relationship of organizational politics and support to work behaviors, attitudes, and stress. Journal of Organizational Behavior, 18(2), 159-180.

Dasborough, M. T., \& Ashkanasy, N. M. (2002). Emotion and attribution of intentionality in leader-member relationships. The Leadership Quarterly, 13(5), 615-634.

Deal, T. E., \& Peterson, K. D. (1999). Shaping school culture: The heart of leadership. Jossey-Bass Inc., Publishers, 350 Sansome Street, San Francisco, CA 94104.

Dean, L. R. (1954). Union activity and dual loyalty. Industrial and Labor Relations Review, 526-536.

Den Hartog, D. N., \& De Hoogh, A. H. (2009). Empowering behavior and leader fairness and integrity: Studying perceptions of ethical leader behavior from a levels-of-analysis perspective. European Journal of Work and Organizational Psychology, 18(2), 199-230.

Den Hartog, D. N., House, R. J., Hanges, P. J., RuizQuintanilla, S. A., \& Dorfman, P. W. (1999). Culture specific and cross-culturally generalizable implicit leadership theories: Are attributes of charismatic/ transformational leadership universally endorsed? 11The first five authors participated in the statistical analyses and the writing of this monograph. The Senior Research Associates provided general research support to the Principal Investigator and the GLOBE Coordinating Team, assisted country representatives in translation and back-translations of instruments and in data collection, and .... The Leadership Quarterly, 10(2), 219-256.

Detert, J. R., Trevino, L. K., Burris, E. R., \& Andiappan, M. (2007). Managerial modes of influence and counter productivity in organizations: a longitudinal business-unit-level investigation. Journal of Applied Psychology, 92(4), p328.

Dirks, K. T., \& Ferrin, D. L. (2002). Trust in leadership: meta-analytic findings and implications for research and practice. Journal of applied psychology,87(4),
611.

Dollard, M. F. (2007). Psychosocial safety culture and climate; definition of a new construct. Adelaide: Work and Stress Research Group, University of South Australia.

Edmondson, A. (1999). Psychological safety and learning behavior in work teams. Administrative Science Quarterly, 44(2), 350-383.

Eisenbeiss, S. A. (2012). Re-thinking ethical leadership: An interdisciplinary integrative approach. Leadership Quarterly, 23(5), 791-808.

Everton, W.J., Jolton, J.A. and Mastrangelo, P.M., 2007. $\mathrm{Be}$ nice and fair or else: understanding reasons for employees' deviant behaviours, Journal of Management Development, 26(2): 117-131

Fagbohungbe, B. O., Akinbode, G. A., \&Ayodeji, F. (2012). Organizational determinants of workplace deviant behaviours: An empirical analysis in Nigeria. International Journal of Business and Management, 7(5), 207-221.

Garrick, A., Mak, A. S., Cathcart, S., Winwood, P. C., Bakker, A. B., \& Lushington, K. (2014). Psychosocial safety climate moderating the effects of daily job demands and recovery on fatigue and work engagement. Journal of Occupational and Organizational Psychology, 87(4), 694-714.

Hall GB, Dollard MF, Coward J(2010). Psychosocial safety climate: development of the PSC-12. International Journal of Stress Management 4, 353-383

Harris, L. C., \&Ogbonna, E. (2002).Exploring service sabotage the antecedents, types and consequences of frontline, deviant, antiservicebehaviors. Journal of Service Research, 4(3), 163-183.

Hester, K., \& Fuller, J. B. (2001).Building Union Commitment: The Impact of Parental Attitudes and Participation. Labor Studies Journal, 26(2), 17-30.

Hollinger, R. C., \& Clark, J. P. (1982). Formal and Informal Social Controls of Employee.

Holloway, J. B. (2012). Leadership Behavior and organizational climate: An empirical study in a non-profit organization. Emerging Leadership Journeys, 5(1), 9-35.

Iverson, R. D., \&Kuruvilla, S. (1995). Antecedents of union loyalty: The influence of individual dispositions and organizational context. Journal of Organizational Behavior, 16(6), 557-582.

James, L.R., Choi, C.C., Ko, C.E., McNeil, P.K., Minton, M.K., Wright, M.A., Kim, K.,2008. Organisational and psychological climate: a review of theory and research. European Journal of Work and Organisational Psychology 17, 5-32

Kacmar, K. M., Bachrach, D. G., Harris, K. J., \& Zivnuska, S. (2011). Fostering good citizenship 
through ethical leadership: exploring the moderating role of gender and organizational politics. Journal of Applied Psychology, 96(3), 633-642.

Kalshoven, K., Den Hartog, D. N., \& De Hoogh, A. H. B. (2012). Ethical leadership and follower helping and courtesy: Moral awareness and empathic concern as moderators. Applied Psychology, 62(2), 211-235.

Kelloway, E. K., Catano, V. M., \& Southwell, R. R. (1992). The construct validity of union commitment: Development and dimensionality of a shorter scale. Journal of Occupational and Organizational Psychology, 65(3), 197-211.

Kidwell, R.E. and Valentine, S.R., 2009. Positive Group Context, Work Attitudes, and Organizational Misbehavior: The Case of Withholding Job Effort. Journal of Business Ethics, 86: 15-28.

Klotz, A.C. and Buckley, M.R., 2013, A historical perspective of counterproductive work behaviortargeting the organization. Journal of Management History, 19(1): 114 - 132.

Kochan, T. A. (1979). How American workers view labor unions. Monthly Lab. Rev., 102, p23.

Kristof-Brown, A. L., Zimmerman, R. D., \& Johnson, E. C. (2005). Consequences of individuals'fit at work: a meta-analysis of person-job, personorganization, person-group, and person-supervisor fit. Personnel Psychology, 58(2), 281-342.

Kuruvilla, S., Gallagher, D. G., Fiorito, J., \& Wakabayashi, M. (1990). Union participation in Japan: Do western theories apply?. Industrial \& Labor Relations Review, 43(4), 374-389.

Ladd Jr, E. C., \&Lipset, S. M. (1973).Professors, Unions, and American Higher Education.

Larson, E. W., \&Fukami, C. V. (1984). Relationships Between Worker Behavior and Commitment to the Organization and Union. Academy of Management Proceedings (Vol 1, pp. 222-226).

Larson, E. W., \&Fukami, C. V. (1984, August). Relationships Between Worker Behavior and Commitment to the Organization and Union. In Academy of Management Proceedings (Vol. 1984, No. 1, pp. 222-226).Academy of Management.

LaVan, H., \& Martin, W. M. (2008).Bullying in the US workplace: Normative and process-oriented ethical approaches. Journal of Business Ethics, 83(2), 147-165.

Law, R., Dollard, M. F., Tuckey, M. R., \& Dormann, C. (2011). Psychosocial safety climate as a lead indicator of workplace bullying and harassment, job resources, psychological health and employee engagement. Accident Analysis \& Prevention, 43(5), 1782-1793.

Law, R., Dollard, M. F., Tuckey, M. R., \& Dormann,
C. (2011).Psychosocial safety climate as a lead indicator of workplace bullying and harassment, job resources, psychological health and employee engagement. Accident Analysis \& Prevention, 43(5), 1782-1793.

Lee, K., \& Allen, N. J. (2002). Organizational citizenship behavior and workplace deviance: the role of affect and cognitions. Journal of Applied Psychology, 87(1), 131-142.

Liden, R. C., Wayne, S. J., Zhao, H., \& Henderson, D. (2008). Servant leadership: Development of a multidimensional measure and multi-level assessment. The Leadership Quarterly, 19(2), 161177.

Litzky, B.E., Eddleston, K.A. and Kidder, D.L., 2006. The Good, the Bad, and the Misguided: How Managers Inadvertently Encourage Deviant Behaviors. Academy of Management Perspectives, 91-103.

Mayer, D. M., Kuenzi, M., \& Greenbaum, R. L. (2010). Examining the link between ethical leadership and employee misconduct: The mediating role of ethical climate. Journal of Business Ethics, 95(1), 7-16.

Mayer, D.M., Kuenzi, M., Greenbaum, R. L., Bardes, M., \& Salvador, R. (2009). How low does ethical leadership flow? Test of a trickle-down model. Organizational Behavior and Human Decision Processes, 108(1), 1-13.

Mayer, R. C., Davis, J. H., \& Schoorman, F. D. (1995). An integrative model of organizational trust. Academy of Management Review, 20(3), 709-734.

McAllister, D. J. (1995). Affect-and cognition-based trust as foundations for interpersonal cooperation in organizations. Academy of Management Journal, 38(1), 24-59.

Neubert, M. J., Carlson, D. S., Kacmar, K. M., Roberts, J. A., \& Chonko, L. B. (2009). The virtuous influence of ethical leadership behavior: Evidence from the field. Journal of Business Ethics, 90(2), 157-170.

Parks, J. M., Gallagher, D. G., \& Fullagar, C. J. (1995). Operationalizing the outcomes of union commitment: The dimensionality of participation. Journal of Organizational Behavior, 16(6), 533555.

Piccolo, R. F., Greenbaum, R. L., Den Hartog, D. N., \& Folger, R. (2010). The relationship between ethical leadership and core job characteristics. Journal of Organizational Behavior, 31(April 2009), 259278.

Posner, B. Z., \& Schmidt, W. H. (1992). Values and the American manager: An update updated. California Management Review, 34(3), 80-94.

Reave, L. (2005). Spiritual values and practices related 
to leadership effectiveness. The Leadership Quarterly, 16(5), 655-687.

Resick, C. J., Hanges, P. J., Dickson, M. W., \& Mitchelson, J. K. (2006). A cross-cultural examination of the endorsement of ethical leadership. Journal of Business Ethics, 63, 345-359.

Riggle, R. J. (2007). The impact of organizational climate variables of perceived organizational support, workplace isolation, and ethical climate on salesperson psychological and behavioral work outcomes. ProQuest. p96.

Robinson, S. L. \& Bennett, R. J. (1995). A typology of deviant workplace behaviours: A multidimensional scaling study. Academy of Management Journal, $38,555-572$.

Schaubroeck, J. M., Hannah, S. T., Avolio, B. J., Kozlowski, S. W., Lord, R. G., Treviño, L. K., et al. (2012). Embedding ethical leadership within and across organization levels. Academy of Management Journal, 55(5), 1053-1078.

Schminke, M., Ambrose, M. L., \& Neubaum, D. O. (2005). The effect of leader moral development on ethical climate and employee attitudes. Organizational Behavior and Human Decision Processes, 97(2), 135-151.

Sinclair, R. R., \& Tetrick, L. E. (1995). Social exchange and union commitment: A comparison of union instrumentality and union support perceptions. Journal of Organizational Behavior, 16(S1), 669680.

Stagner, R. (1954). Attitude toward authority: an exploratory study. The Journal of SocialPsychology, 40(2), 197-210.

Tepper, B. J., Carr, J. C., Breaux, D. M., Geider, S., Hu, C.,
\& Hua, W. (2009). Abusive supervision, intentions to quit, and employees' workplace deviance: A power/dependence analysis. Organizational Behavior and Human Decision Processes, 109(2), 156-167.

Treviño, L. K., Brown, M., \& Hartman, L. P. (2003). A qualitative investigation of perceived executive ethical leadership: Perceptions from inside and outside the executive suite. Human Relations, 56(1), 5-37.

Trevino, L. K., Hartman, L. P., \& Brown, M. (2000). Moral person and moral manager: How executives develop a reputation for ethical leadership. California Management Review, 42(4), 128-142.

Trevino, L. K., Hartman, L. P., \& Brown, M. (2000). Moral person and moral manager: How executives develop a reputation for ethical leadership. California Management Review, 42(4), 128-142.

Van Knippenberg, D., \&Sitkin, S. B. (2013). A critical assessment of charismatic - Transformational leadership research: Back to the drawing board? The Academy of Management Annals, 7(1), 1-60.

Walumbwa, F. O., \& Schaubroeck, J. (2009). Leader personality traits and employee voice behavior: mediating roles of ethical leadership and work group psychological safety. Journal of Applied Psychology, 94(5), 1275-1286.

Warren, D. E. (2003). Constructive and destructive deviance in organizations. Academy of Management Review, 28(4), 622-632.

Weaver, G. R., Treviño, L. K., \& Agle, B. (2005). “Somebody I Look Up To:": Ethical Role Models in Organizations. Organizational Dynamics, 34(4), 313-330. 